\title{
Study of protective efficiency of respirator with forced air supply
}

\author{
Nataliia Borodina A; Serhii Cheberiachko * B; Yurii Cheberyachko ${ }^{\text {B; }}$ Oleg Deryugin ${ }^{\text {B; }}$; \\ Dmytro Radchuk ${ }^{\mathrm{B}}$; Daniil Klimov ${ }^{\mathrm{B}}$; \\ A Bilotserkivsky Institute of Continuous Professional Education, 54/2, Levanevskjgo, str., Bila Tserkva, 09100, Ukraine \\ ${ }^{B}$ Dnipro University of Technology, 19, Dmytra Yavornytskoho ave., Dnipro, 49005, Ukraine
}

Received: November 07, 2020 | Revised: December 05, 2020 | Accepted: December 31, 2020

DOI: $10.33445 /$ sds.2020.10.6.18

\begin{abstract}
The aim of the work was to conduct experimental studies aimed at determining the protection factor of the filter respirator with forced air supply by volunteers in different modes of operation and to establish the dependence of the amount of air supplied by the fan from the air purification device to the filter's resistance. Simulation studies to determine the protective effectiveness of the filter respirator on the testers were performed according to the procedure for determining the penetration coefficient of test aerosol - sodium chloride, as the ratio of the submask concentration of test aerosol to the ambient concentration formed in a special chamber that meets the requirements of DSTU EN 13274. Determination of the amount of air supplied by the air purification unit to the submask space and assessment of the value of positive pressure inside the mask was performed according to the procedure described in DSTU EN 12941: 2004. As a result of simulated laboratory tests to determine the protective effectiveness of filter respirators with forced air supply to the testers, it was found that the average result of the protection factor of the test samples ranged from 99.93 to 99.97, which meets the requirements of DSTU EN 12941: 2004. In addition, it was found that the amount of air treated by the fan of the air purification device for clean filters is 165 and $215 \mathrm{dm}^{3} / \mathrm{min}$ for operating modes "Normal" and "Turbo", while for the polluted filters it is reduced to 131 and $185 \mathrm{dm}^{3} / \mathrm{min}$, respectively. During the study, the compliance of the value of excess pressure in the submask space with the requirements of DSTU EN 12941: 2004, which should not exceed 2.5 mbar, was confirmed. It is also determined that the stability of the technical parameters of the air purification device is maintained in the specified range when charging the "Dinogy Li-Pol $11000 \mathrm{mAh} 14.8 \mathrm{~V} 4 \mathrm{~S} 25 \mathrm{C}$ " brand battery not less than $12 \mathrm{~V}$ to ensure the current value of not less than 1.6 A. The practical value of the results lies in determining the duration of protective action of the filter respirator, the choice of filter resistance to establish the scope and modes of operation in the developed personal respiratory protection equipment.
\end{abstract}

Key words: powered air-purifying respirator, protection factor, respiratory resistance.

\section{Introduction}

Powered air-purifying respirators (PAPR) with forced air supply are characterized by a number of advantages in comparison with filtering personal respiratory protection equipment (PRPE) working on a negative pressure differential. First of all, such respirators have a much higher degree of protection (Institute of Medicine. 2015), which allows their use when working with toxic substances or in the absence of respiratory resistance. That is, they will be useful for intensive and hard work, and the workers, who for various reasons could not choose a mask (half mask) with a tight fit to the face, including the presence of hair on the face (Radonovich, L. J. Jr., Yanke, R.,

\footnotetext{
* Corresponding author: Doctor of Technical Science (D.Sc.), Professor of the Department of Labor Protection and Civil Safety, e-mail: sicheb@ukr.net, ORCID: 0000-0003-3281-7157
} 
Cheng, J., \& Bender, B., 2010), can use them. In addition, powered respirators do not accumulate additional heat, which is provided by the constant supply of air flow into the submask space (Khoo, K.L., Leng, P.H., Ibrahim, I.B., \& Lim, T.K., 2005). In some countries of the world, including the USA, Great Britain, Japan, South Korea, the industry manufactures several types of the considered devices. Their design consists of the following elements - a protective mask (half mask, hood, helmet-mask), which is connected by a flexible air duct with an air purifier equipped with one or more filter elements. The air purifier is a housing with a radial fan with an electric drive, which is powered by a battery and controlled through an electro-pneumatic system. This system analyzes the pressure drop with the help of a processor, and then transmits a special code to turn on / off the blower fan to increase / decrease the flow of air entering the submask space of the helmetmask (depending on the volume of air inhaled by the worker and his physical load when performing the production activities). However, the above design has several disadvantages, namely:

- low efficiency of the blower fan due to the significant resistance to air flow that occurs in the air duct, due to the relatively small size of the air ducts, and therefore the need to operate at high speeds, which causes significant noise and leads to rapid reduction of battery charge, which in turn reduces the service life of its use;

- inefficient operation of the device control system, which in cases of a sharp increase in air flow, for example, due to heavy work, turns on the fan with a delay, which leads to the formation of negative pressure under the mask, and therefore can lead to suction of unfiltered air behind the obturation strip (seal between mask and face or seal dust mask), as well as to increase the concentration of carbon dioxide in the submask space, which can lead to deterioration of the employee's health;

- low performance of the blower fan, which does not allow its use in an atmosphere contaminated with several different harmful substances, which requires the installation of several gas filters for protection that are installed in series. Therefore, the development of an effective respirator with forced air supply, in order to minimize the impact of harmful substances contained in the atmosphere of the working environment on the respiratory organs of the worker during production activities is an urgent task for manufacturers of personal protective equipment.

Powered air-purifying respirators (PAPR) with forced air supply are characterized by a number of advantages in comparison with filtering personal respiratory protection equipment (PRPE) working on a negative pressure differential. First of all, such respirators have a much higher degree of protection (Institute of Medicine, 2015), which allows their use when working with toxic substances or in the absence of respiratory resistance. That is, they will be useful for intensive and hard work, and the workers, who for various reasons could not choose a mask (half mask) with a tight fit to the face, including the presence of hair on the face (Radonovich, L. J. Jr., Yanke, R., Cheng, J., \& Bender, B., 2010), can use them. In addition, powered respirators do not accumulate additional heat, which is provided by the constant supply of air flow into the submask space (Khoo, K.L., Leng, P.H., Ibrahim, I.B., \& Lim, T.K., 2005). In some countries of the world, including the USA, Great Britain, Japan, South Korea, the industry manufactures several types of the considered devices. Their design consists of the following elements - a protective mask (half mask, hood, helmet-mask), which is connected by a flexible air duct with an air purifier equipped with one or more filter elements. The air purifier is a housing with a radial fan with an electric drive, which is powered by a battery and controlled through an electro-pneumatic system. This system analyzes the pressure drop with the help of a processor, and then transmits a special code to turn on / off the blower fan to increase / decrease the flow of air entering the submask space of the helmetmask (depending on the volume of air inhaled by the worker and his physical load when performing the production activities). However, the above design has several disadvantages, namely: 
- low efficiency of the blower fan due to the significant resistance to air flow that occurs in the air duct, due to the relatively small size of the air ducts, and therefore the need to operate at high speeds, which causes significant noise and leads to rapid reduction of battery charge, which in turn reduces the service life of its use;

- inefficient operation of the device control system, which in cases of a sharp increase in air flow, for example, due to heavy work, turns on the fan with a delay, which leads to the formation of negative pressure under the mask, and therefore can lead to suction of unfiltered air behind the obturation strip (seal between mask and face or seal dust mask), as well as to increase the concentration of carbon dioxide in the submask space, which can lead to deterioration of the employee's health;

- low performance of the blower fan, which does not allow its use in an atmosphere contaminated with several different harmful substances, which requires the installation of several gas filters for protection that are installed in series. Therefore, the development of an effective respirator with forced air supply, in order to minimize the impact of harmful substances contained in the atmosphere of the working environment on the respiratory organs of the worker during production activities is an urgent task for manufacturers of personal protective equipment.

During long-term or intensive work, filter respirators with forced air supply are used to reduce the negative impact of respiratory resistance, elevated temperature, as well as to improve the ventilation of the sub-mask space.
Employees of the Department of Occupational Safety and Civil Safety of the National Technical University "Dnipro Polytechnic" for the first time created a similar filter powered PRPE, which includes a mask with an obturator, inhalation and exhalation valves, flexible corrugated air duct connected to an air purifier with filters, in which a fan, a control unit and power supply unit are placed (Fig. 1). These PRPE differs from the known designs by the presence in of the air flow control unit the air purification device due to the multifunctional system of sensors, which allow providing in the automatic mode of regulation of the main parameters of the air flow in the mask space. It is known that this type of device has a number of requirements, the implementation of which guarantees their high protective properties. In particular, ensuring that the volume of supplied air in the submask space is not less than 120 $\mathrm{dm}^{3} / \mathrm{min}$. with the possibility of increasing to 170 $\mathrm{dm}^{3} / \mathrm{min}$., provided that the resistance of filters is up to 15 mbar. This value will maintain a positive pressure in the submask space, thereby eliminating the suction due to leaks behind the obturation strip. In addition, one of the important indicators is the protection factor, the value of which must be at least 99.9. Therefore, there is a task of checking the main indicators of the protective effectiveness of a powered filter respirator with forced air supply.

The aim of this work is experimental research aimed at determining the protection factor of the filter respirator with forced air supply on volunteers and establishing the dependence of air flow in the submask space on the resistance of the filters of the purification device.

\section{Material and methods}

The research was based on the experimental test procedure, which included determining the penetration and protection coefficients of the filter respirator with forced air supply by test aerosol - sodium chloride on test volunteers, determining the flow of air supplied by the air purification unit to the submask space and determining the positive pressure inside the helmet or hood in accordance with the requirements of the standard (DSTU EN 12941:2004).

The test of the protective efficiency of the filter respirator with forced air supply was performed on a special stand (Figure 2), which meets the requirements of the standard DSTU EN 13274-1: 2005. It consists of an ultrasonic test aerosol generator, a test chamber where the tester was located, a "Selmi C-115E" 
spectrophotometer (manufactured by "SELMI" LLC: Sumy, Ukraine) with a built-in aspirator for sampling. As a test aerosol $0.1 \%$ sodium chloride solution was used, which was dried and supplied with an air flow rate of $100 \mathrm{dm}^{3} / \mathrm{min}$. into the test chamber.

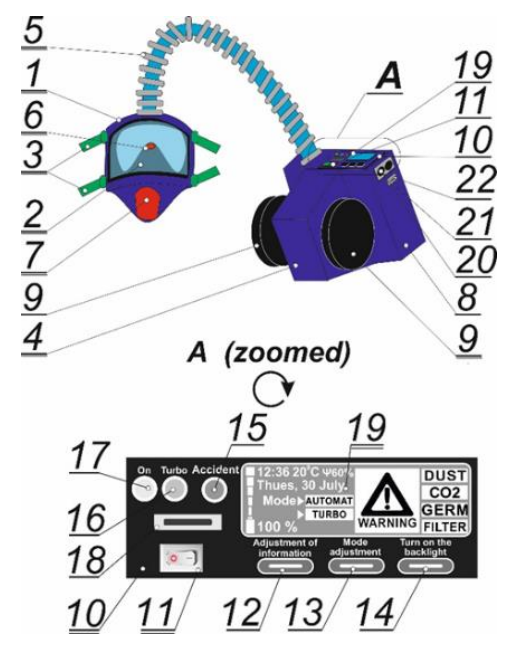

Fig. 1. Schematic diagram of a filter respirator with forced air supply: helmet-mask (1), obturator (2), head straps (3), air purification device (4), flexible corrugated air duct (5), inhalation valve (6), exhalation valve (7), air cleaner housing (8), filter elements (9), control unit (10), on/off switch

(11), button №1 (12) - "Information correction" (time, day of the week, month, ambient temperature, humidity); button №2 (13) "Mode adjustment" (automatic mode, turbo mode, emergency mode); button №3 (14) - "Display backlight"; indicator lights: - red indicator light (15)

- "Accident", blue indicator light (16) - "Turbo", green indicator light (17), memory card (18), display (19), loudspeaker (20), connector for charging batteries (21), USB connector for connection to a PC for setting up and adjusting the software of the air cleaning device (22)

The test aerosol generator provided the distribution of aerosol particles in the range from 0.02 to $2 \mu \mathrm{m}$ with a weight average diameter of 0.6 $\mu \mathrm{m}$. Uniformity of its distribution in the test chamber was ensured by ventilation and test aerosol supply systems. The concentration in the respiratory zone of the tester during the studies was constantly monitored and was $8 \pm 4 \mathrm{mg} / \mathrm{m}^{3}$.
To measure the concentration under the respirator mask, a special sampler was used, which sucked air between the nose and lips. Samples of the aerosol mixture in the chamber and in the mask space of the respirator were taken simultaneously. At the same time, the sampling in the chamber and in the submask space was at the same level (Figure 3).
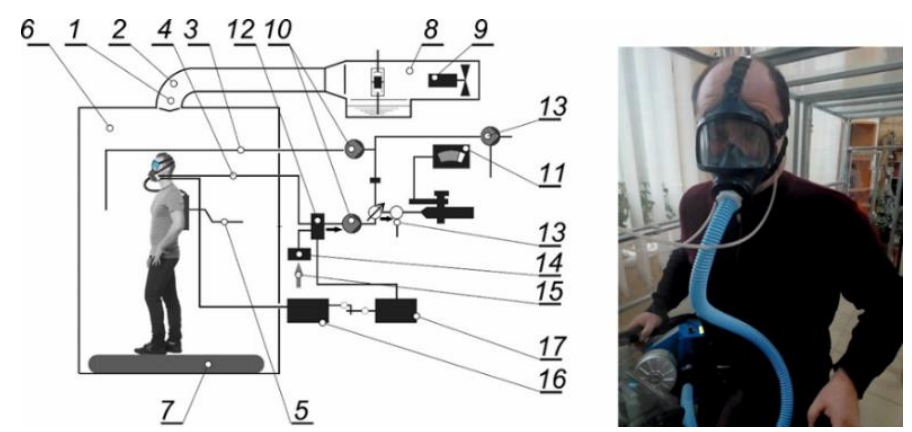

Fig. 2. Test facility for determining the penetration rate of sodium chloride: 1 - deflector; 2 - pipeline; 3 - sampling line of the atmosphere in the chamber; 4-sampling from the submask space; 5 - supply of respiratory air; 6 - test chamber; 7 -treadmill; 8 -sprayer; 9 -fan; 10 -pump; 11 - photometer; 12 - switching valve; 13 - additional air supply; 14 - filter; 15 - clean air; 16 - manometer; 17 - system of separation of phases of inhalation and exhalation 


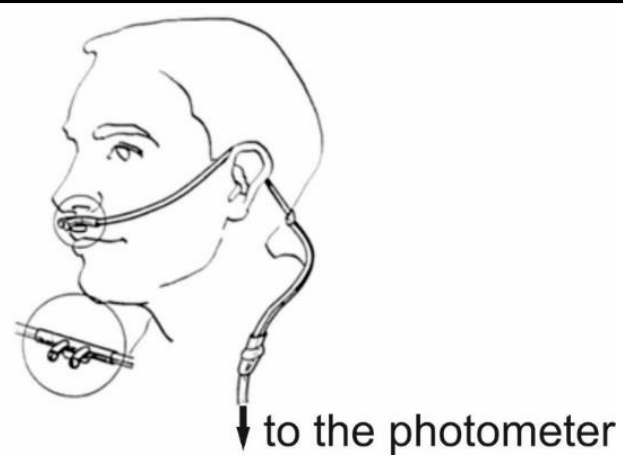

Fig. 3. Scheme of the sampling probe

The suction rate of air in both in the first and in the second case was $3 \mathrm{dm}^{3} / \mathrm{min}$. During testing, the test sample was equipped with FRPA P2 "particle filter" filters of the second class of protection, which met the requirements of the standard (DSTU EN 143: 2002), i.e. their coefficient of penetration of the test aerosol was not more than $6 \%$. As a result of the experimental study, the total protection factor of the respirator with forced air supply was determined by the formula:

$$
P F=\frac{100}{K_{p}}
$$

Where $K p$ is the penetration coefficient of the test aerosol, which reflects the penetration of the aerosol through the filter and the sealing strip between the face and the half mask.

The test involved six volunteers (Caucasians): two women and four men, aged 23 to 44 years, according to the parametric size of the face (Table 1), who were previously instructed on the proper use of a filter respirator and checked the correctness of its fit to the face. If in the process of testing there was a need to adjust the fixing of the half mask, then there was a stop for fixing the value of the submask concentration of the test aerosol, which was resumed after the restoration of the original parameters of the system.

During the study, the testers performed sequentially the exercises provided by the standard (DSTU EN 12941:2004): normal breathing; deep breathing; head movements from side to side; head movements up and down; conversation aloud; walking on a treadmill at a speed of $6 \mathrm{~km} / \mathrm{h}$. In addition, squats, tilts and turns of the torso were reproduced to simulate production operations; work on dismantling the blockages was simulated (since this device can be used to eliminate emergencies and provide assistance to victims).

Table 1 - Dimensions of the faces of the participants of the experiment

\begin{tabular}{|c|c|c|c|}
\hline \multirow{2}{*}{ Face height, $\mathrm{mm}$} & \multicolumn{3}{|c|}{ Face width, $\mathrm{mm}$} \\
\cline { 2 - 4 } & $\begin{array}{l}129-139 \\
\text { (1 zone) }\end{array}$ & $\begin{array}{l}140-145 \\
(2 \text { zone })\end{array}$ & $\begin{array}{l}146-155 \\
\text { (3 zone) }\end{array}$ \\
\hline $136-126$ & 1 tester & 1 tester & - \\
\hline $125-116$ & 1 tester & 1 tester & 1 tester \\
\hline $115-105$ & - & & 1 tester \\
\hline
\end{tabular}

Each exercise was performed for 2 minutes. Each tester was made three measurements for each exercise. The result was averaged and entered in a special table in the program "AAS2009", which provides for the definition of statistics in accordance with the requirements of the standard (ISO 5725-6:1994).

Before the start of the study, the testers were trained to prepare the device for work and its operation in automatic ("normal") and "turbo" modes. Prior to testing, all batteries were charged to $100 \%$ of their capacity, by monitoring the voltage and internal resistance of each battery cell separately. Subsequently, the battery was connected to a purification unit with a value of DC magnitude of $1.7 \mathrm{~A}$. During the tests, the indication of voltage levels was carried out according to the indicators installed on the information panel.

The next indicator to be checked was the consumption of purified air supplied to the submask space of the filter PRPE with forced air supply. To do this, a protective mask was put on the mannequin of the head. The air flow, which was fed into the submask space through a tube inserted into the mannequin, got to the flow meter PM-0.4-1.6, by which the air amount was determined, while using an electronic micromanometer ("Testo 512") to monitor the level of difference pressure (Fig. 4). 


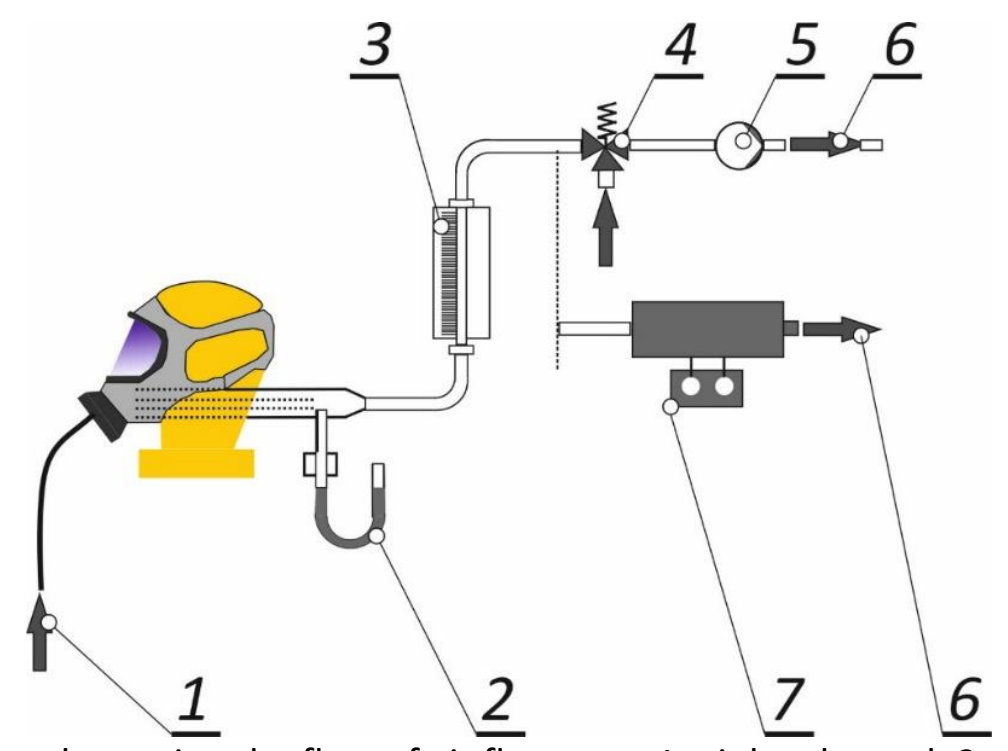

Fig. 4. Test facility to determine the flow of air flow rate: 1 - inlet channel; 2 - micromanometer; 3 - flow meter; 4 - regulator; 5 - suction device; 6 - outlet; 7 - power regulator

Instability of maintaining a given level of air flow, which was calculated on the basis of experimental data by the formula:

$$
\delta_{Q}=\frac{\left(Q_{\max }-Q_{\min }\right)}{\bar{Q}} \cdot 100, \%
$$

Where $Q_{\max }, Q_{\min }, \bar{Q}_{i}$ - the maximum, minimum and arithmetic mean of the experimentally determined data; $\delta_{Q}$ - instability of air flow during continuous operation of the device.

\section{Results and discussion}

The results of experimental studies of the averaged protection coefficients of test samples of filter respirator with forced air supply by test aerosol of sodium chloride on volunteers are shown in Table 2. The tests were performed on two modes "Normal" and "Turbo", the main difference between which was the air consumption fed the submask space of the filter device.

The next step was to check the maximum air flow that can be developed by a filter respirator with forced air supply equipped with gas filters with air flow resistance at a flow rate of 95 $\mathrm{dm}^{3} / \mathrm{min} 3.1$ mbar, which meets the requirements of the standard [18]. The change in filter resistance with increased air flow rate is shown in Table 3 . The results obtained at different operating modes for a clean filter are shown in Figure 5 and for the maximum spent filter (spent filter $\Delta \mathrm{P} \geq 15$ mbar) - in Figure 6 . This study is in accordance with the standard (Harber, P., Yun, D., Santiago, S., Bansal, S., \& Liu, Y., 2011) and it is held for one hour to demonstrate the stability of the results. According to the requirements of (DSTU EN 12941:2004), the volume of air entering the mask from the air purification device per time unit must be at least $120 \mathrm{dm}^{3} / \mathrm{min}$. As can be seen from the graphs shown in Figures 5 and 6 , the air flow rate through the clean filters for the operating modes "Normal" and "Turbo" reaches 165 and $215 \mathrm{dm}^{3} / \mathrm{min}$, respectively, and through the polluted filters -131 and $185 \mathrm{dm}^{3} / \mathrm{min}$.

Experimental determination of excess (positive) pressure generated by the purification unit in the "Normal" and "Turbo" modes in the helmet space of the filter respirator with forced air supply are given in Table 4. 
Table 2 - Determination of the protection factor of the filter respirator with forced air supply in the modes "Normal" and "Turbo" on volunteers

\begin{tabular}{|c|c|c|c|c|}
\hline \multirow{2}{*}{ Tester } & $\begin{array}{c}\text { Air purifier operation } \\
\text { mode }\end{array}$ & $\begin{array}{c}\text { Air flow rate } \\
\mathrm{dm}^{3} / \mathrm{min} .\end{array}$ & $\begin{array}{c}\text { Filter resistance, } \\
\mathrm{mbar}\end{array}$ & $\begin{array}{c}\text { Protection } \\
\text { coefficient }\end{array}$ \\
\hline \multirow{2}{*}{1} & "Normal" & 102 & 3,3 & 99,95 \\
\cline { 2 - 5 } & "Turbo" & 143 & 5,6 & 99,97 \\
\hline \multirow{2}{*}{2} & "Normal" & 108 & 3,5 & 99,98 \\
\cline { 2 - 5 } & "Turbo" & 146 & 5,7 & 99,93 \\
\hline \multirow{2}{*}{3} & "Normal" & 101 & 3,4 & 99,95 \\
\cline { 2 - 5 } & "Turbo" & 155 & 6,1 & 99,96 \\
\hline \multirow{2}{*}{4} & "Normal" & 107 & 3,4 & 99,99 \\
\cline { 2 - 5 } & "Turbo" & 145 & 5,7 & 99,97 \\
\hline \multirow{2}{*}{5} & "Normal" & 97 & 3,1 & 99,93 \\
\cline { 2 - 5 } & "Turbo" & 143 & 5,4 & 99,95 \\
\hline \multirow{2}{*}{6} & "Normal" & 109 & 3,8 & 99,97 \\
\cline { 2 - 5 } & "Turbo" & 146 & 5,6 & 99,96 \\
\hline
\end{tabular}

Table 3 - The results of measuring the air flow resistance of the filters of the respirator with forced air supply

\begin{tabular}{|c|c|c|}
\hline Air flow rate, $\mathrm{dm}^{3} / \mathrm{min}$. & $\begin{array}{c}\text { The maximum value of resistance at different values of air } \\
\text { flow rate, mbar }\end{array}$ & Deviation, \% \\
\hline 95 & 3,1 & 6,0 \\
\hline 120 & 4,3 & 2,3 \\
\hline 160 & 6,1 & 1,6 \\
\hline 197 & 8,1 & 3,7 \\
\hline
\end{tabular}

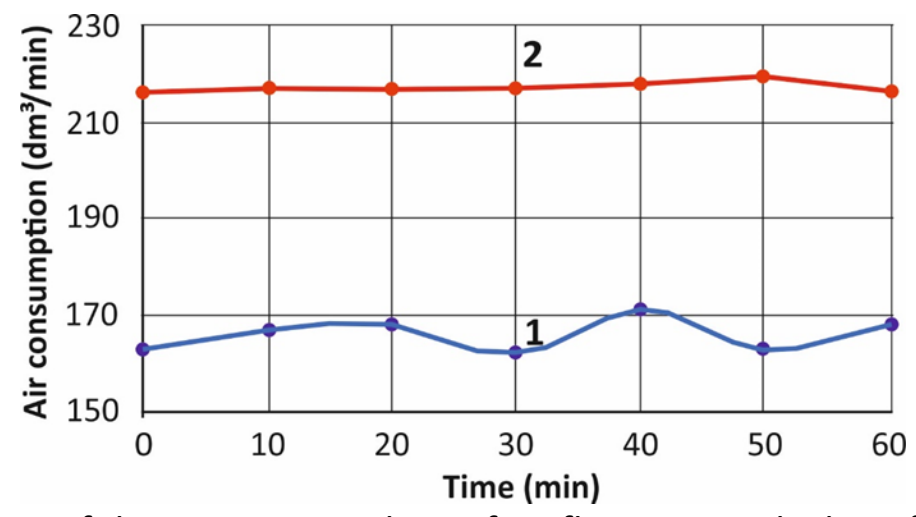

Fig. 5. Determination of the maximum values of air flow rate with clean filters in the modes

"Normal" (1) and "Turbo" (2) of the filter respirator with forced air supply

Table 4 - The results of measuring the excess pressure in the submask space of the filter respirator with forced air supply with clean filters

\begin{tabular}{|c|c|c|}
\hline \multirow{2}{*}{ Tested samples } & \multicolumn{2}{|c|}{ Excess pressure, mbar in the modes } \\
\cline { 2 - 3 } & "Normal" & "Turbo" \\
\hline 1 & 1,5 & 2,2 \\
\hline 2 & 1,7 & 2,5 \\
\hline 3 & 1,7 & 2,1 \\
\hline 4 & 1,6 & 2,2 \\
\hline 5 & 1,5 & 2,4 \\
\hline 6 & 1,7 & 2,5 \\
\hline
\end{tabular}




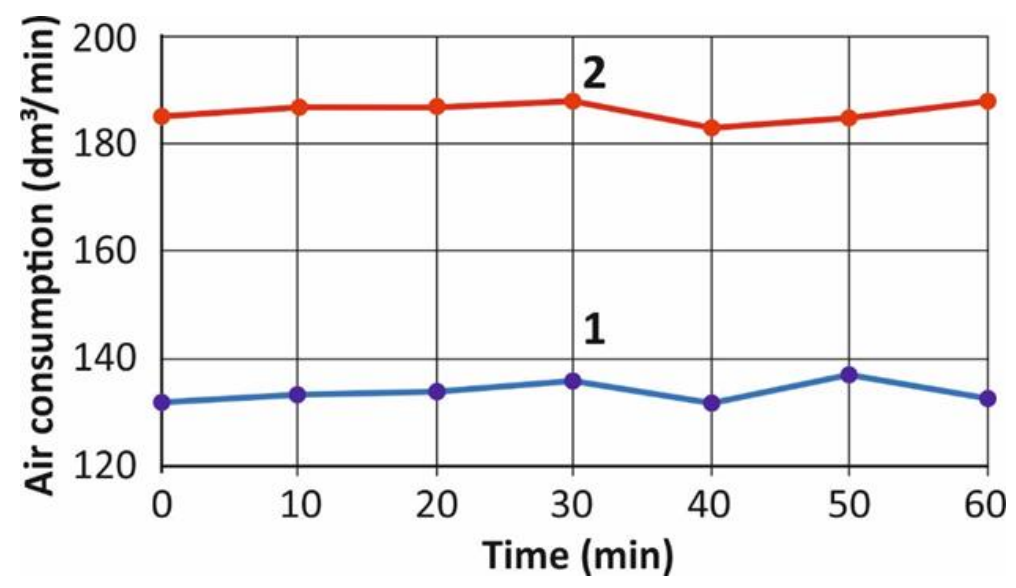

Fig. 6. Determination of the maximum values of air flow rate with the most polluted filters of the filter respirator with forced air supply with the resistance $\Delta \mathrm{P} \geq 15$ mbar in the modes "Normal" (1) and "Turbo" (2)

A certain advantage of this study over laboratory tests, which are regulated by the relevant standard (DSTU EN 12941:2004) was the ability to measure the protective effectiveness not only at the minimum technical parameters of the air purifier, but also at the maximum indicator values, which are characterized by increased air flow rate. It was assumed that with increasing the air flow rate, the protective efficiency will improve due to the increase of positive pressure in the submask space, which was proved during the tests (Table 2). However, it is still possible to increase the penetration rate of the test aerosol through the filters, due to the increase in filtration rate, and hence the shorter residence time of aerosol particles in the inner space of the filters, which worsens the effect of particles trapping (Cohen, H. J., Hecker, L. H., Mattheis, D. K., Johnson, J. S., Biermann, A. H., \& Foote, K. L., 2001). The obtained average result of the protection factor of the tested samples ranged from 99.93 to 99.97. This confirms that a sufficient positive pressure was created in the submask space, which makes it impossible to absorb aerosol particles due to leaks in the obturation strip. The available range of scatter of results is explained by the inhomogeneity of the penetration coefficient of the filter elements used for the tests, but it is within acceptable limits. The obtained result is confirmed by the fact that the fan provides a uniform air flow rate for a specified period. The study also found that during the "Turbo" mode, the volume of air in the submask space was more stable due to the supply of maximum supply voltage, which reduces the system's response to feedback signals from the tachometer to adjust the fan impeller speed. It should be noted that in this situation, the system notifies the user with the appropriate light and sound signal "Replace filter". Additionally, it was found that the experimentally determined excess pressure in the submask space does not exceed $2.5 \mathrm{mbar}$, which fully meets the requirements of paragraph 6.5 of the standard (DSTU EN 12941:2004), according to which it should not be more than 5 mbar. The stability of the technical parameters of the air purifier is maintained in a given range when the battery of the "Dinogy Li-Pol 11000mAh 14.8V 4S 25C" brand is not lower than $12 \mathrm{~V}$ to ensure a current of not less than $1.6 \mathrm{~A}$.

\section{Conclusions}

As a result of simulated laboratory tests to determine the protective effectiveness of filter respirators with forced air supply to the testers, it was found that the average result of the 
protection factor of the test samples ranged from 99.93 to 99.97, which meets the requirements of the standard. In addition, it is determined that the air flow rate is maintained for clean filters at the level of 165 and 215 $\mathrm{dm}^{3} / \mathrm{min}$. for the operating modes "Normal" and "Turbo", respectively, and for contaminated -131 and $185 \mathrm{dm}^{3} / \mathrm{min}$. It is established that the excess pressure in the submask space does not exceed 2.5 mbar, which fully meets the requirements of standard DSTU EN 12941: 2004.
It is also determined that the stability of the technical parameters of the air purification device is maintained in a given range when the battery of "Dinogy Li-Pol 11000mAh 14.8V 4S $25 \mathrm{C}$ " brand is not lower than $12 \mathrm{~V}$ to ensure a current of not less than 1.6 A. Thus, a filter respirator with forced air supply is characterized by high indicators of protective properties, which are maintained at a stable level for a certain period of its operation.

\section{References}

Bharatendu, C., Ong, J.J.Y., Goh, Y., Tan, B.Y.Q., Chan, A.C.Y., Tang, J.Z.Y., Leow, A.S., Chin, A., Sooi, K.W.X., Tan, Yi.L., Chiew, S.H., Chin, B.Z., $\mathrm{Ng}$, E., Foong, T.W., Teoh, H.L., Ong, S.T., Lee, P., Khoo, D., Tsivgoulis, G., Alexandrov, A.V., \& Sharma, V.K. (2020). Powered air purifying respirator (PAPR) restores the $\mathrm{N} 95$ face mask induced cerebral hemodynamic alterations among Healthcare Workers during COVID-19 Outbreak. Journal of the Neurological Sciences. Volume 101(12), p. 1689-93. DOI: 10.1016/j.amjcard.2008.02.056

Candiotti, K. A., Rodriguez, Y., Shekhter, I., Castillo-Pedraza, C., Rosen, L.F., Kristopher, L. A., \& Birnbach, D. J. (2012). A comparison of different types of hazardous material respirators available to anesthesiologists. American journal of disaster medicine. Volume 7(4), p. 313-319. DOI: 10.5055/ajdm.2012.0104

Chughtai, A. A., Chen, X., \& Macintyre, C. R. (2018). Risk of self-contamination during doffing of personal protective equipment. American Journal of Infection Control. Volume 46(12), p. 1329-1334. DOI: 10.1016/j.ajic.2018.06.003

Chughtai, A. A., Seale, H., Rawlinson, W. D., Kunasekaran, M., \& Macintyre, C.R. (2020). Selection and use of respiratory protection by healthcare workers to protect from infectious diseases in hospital settings. Annals of Work Exposures and Health. Volume 64(4), p. 368-377. DOI: 10.1093/annweh/wxaa020

Cohen, H. J., Hecker, L. H., Mattheis, D. K., Johnson, J. S., Biermann, A. H., \& Foote, K. L.
(2001). Simulated workplace protection factor study of powered air-purifying and supplied air respirators. Journal for the Science of Occupational and Environmental Health and Safety. Volume 62(5), p. 595-604. DOI: $10.1080 / 15298660108984658$

DSTU EN 12941:2004 Zasoby indyvidual'noho zakhystu orhaniv dykhannya. Motorovi fil'truval'ni prystroyi $z$ sholomom abo kapyushonom. Vymohy, vyprobovuvannya, markuvannya (EN 12941:1998, IDT) [Respiratory protective devices. Motor filter devices with helmet or hood. Requirements, testing, marking (EN 12941: 1998, IDT)]. Kyiv: Derzhspozhyvstandart Ukrayiny, 2005.

DSTU EN 143: 2002 Respiratory protective devices. Anti-aerosol filters. Requirements, tests, markings (EN 143: 2000 / AC: 2005, IDT). Amendment № 1: 2015 [Respiratory protective devices. Anti-aerosol filters. Requirements, tests, markings (EN 143: 2000 / AC: 2005, IDT). Amendment № 1: 2015]. Kyiv: Derzhspozhyvstandart Ukrainy, 2016.

Harber, P., Yun, D., Santiago, S., Bansal, S., \& Liu, Y. (2011). Respirator impact on work task performance. Journal of Occupational and Environmental Medicine. Volume 53(1), p. 22-26. DOI: 10.1097/JOM.0b013e3181febc75 Institute of Medicine. 2015. The Use and Effectiveness of Powered Air Purifying Respirators in Health Care: Workshop Summary. Washington, DC: The National Academies Press. 80 p. ISBN: 978-0-30931595-1.

ISO 5725-6:1994 Accuracy (trueness and 
precision) of measurement methods and results Part 6: Use in practice of accuracy values. 2017.

Jones, B., \& Nachtsheim, C. J. (2009). Split-plot designs: What, why, and how. Journal of Quality Technology. Volume 41(4), p. 340361. DOI: 10.1080/00224065.2009.11917790

Khoo, K.L., Leng, P.H., Ibrahim, I.B., \& Lim, T.K. (2005). The changing face of healthcare worker perceptions on powered air-purifying respirators during the SARS outbreak. Respirology. Volume 10, p. 107-110. DOI: 10.1111/j.1440-1843.2005.00634.x

Licina, A., Silvers, A., \& Stuart, R.L. (2020). Use of powered air-purifying respirator (PAPR) by healthcare workers for preventing highly infectious viral diseases-a systematic review of evidence. Systematic Reviews. Volume 9(173), p. 1-13. DOI: 10.1186/s13643-02001431-5

Powell, J. B., Kim, J. H., \& Roberge, R. J. (2017). Powered air-purifying respirator use in healthcare: effects on thermal sensations and comfort. Journal of Occupational and Environmental Hygiene. Volume 14(12), p. 947-954. 10.1080/15459624.2017.1358817

Radonovich, L. J. Jr., Yanke, R., Cheng, J., \& Bender, B. (2010). Diminished speech intelligibility associated with certain types of respirators worn by healthcare workers. Journal of Occupational and Environmental Hygiene. Volume 7, p. 63-70. DOI: 10.1080/15459620903404803

Schumacher, J., Arlidge, J., Garnham, F., \& Ahmad, I. (2017). A randomized crossover simulation study comparing the impact of chemical, biological, radiological or nuclear substance personal protection equipment on the performance of advanced life support interventions. Anaesthesia. Volume 72, p.
592-597. DOI:10.1111/anae.13842

Schumacher, J., Gray, S.A., Weidelt, L., Brinker, A., Prior, K., \& Stratling, W.M. (2009). Comparison of powered and conventional air-purifying respirators during simulated resuscitation of casualties contaminated with hazardous substances. The Journal of Emergency Medicine. Volume 26(7), p. 501505. DOI: 10.1136/emj.2008.061531

Verbeek, J.H., Rajamaki, B., Ijaz, S., Tikka, C., Ruotsalainen, J.H., Edmond M.B., Sauni, R., \& Balci, F.S.K. (2020). Personal protective equipment for preventing highly infectious diseases due to exposure to contaminated body fluids in healthcare staff. Cochrane database of systematic reviews. Volume 7(7); p. CD011621.

DOI:

10.1002/14651858.CD011621.pub3

Wagner, N., Boland, S., Taylor, B., Keen, D., Nelson, J., \& Bradley, T. (2010). Powertrain Design for Hand-Launchable Long Endurance Unmanned Aerial Vehicles. $47^{\text {th }}$ AIAA/ASME/SAE/ASEE Joint Propulsion Conference \& Exhibit 31 July 03 August 2011, San Diego, California

Watson, C.M., Duval-Arnould, J.M., McCrory, M.C., Froz, S., Connors, C., Perl, T.M., \& Hunt, E.A. (2011). Simulated pediatric resuscitation use for personal protective equipment adherence measurement and training during the 2009 influenza (H1N1) pandemic. The Joint Commission Journal on Quality and Patient Safety. Volume 37(11), p. 515-523. DOI: 10.1016/s1553-7250(11)37066-3

Wu, S., Harber, P., Yun, D., Bansal, S., Li, Y., \& Santiago, S. (2011). Anxiety during respirator use: Comparison of two respirator types. Journal of Occupational and Environmental Hygiene. Volume 8(3), p. 123-128. DOI: 10.1080/15459624.2011.549780 